\title{
Autonomous Shuttling Driven by an Oscillating Reaction: Proof of Principle in a Cucurbit[7]uril-Bodipy Pseudorotaxane
}

2013

Vol. 15, No. 5

1012-1015

\author{
Onur Buyukcakir, ${ }^{\dagger}$ F.Tuba Yasar, ${ }^{\ddagger}$ O. Altan Bozdemir, ${ }^{\S}$ Burcak Icli," and Engin U. Akkaya ${ }^{\star, \dagger, \neq}$ \\ UNAM-National Nanotechnology Research Center and Department of Chemistry, \\ Bilkent University, 06800 Ankara, Turkey, Department of Chemistry, \\ Ataturk University, 25240 Erzurum, Turkey, and Department of \\ Chemistry, Middle East Technical University, 06800 Ankara, Turkey
}

eua@fen.bilkent.edu.tr

Received December 20, 2012

\section{ABSTRACT}

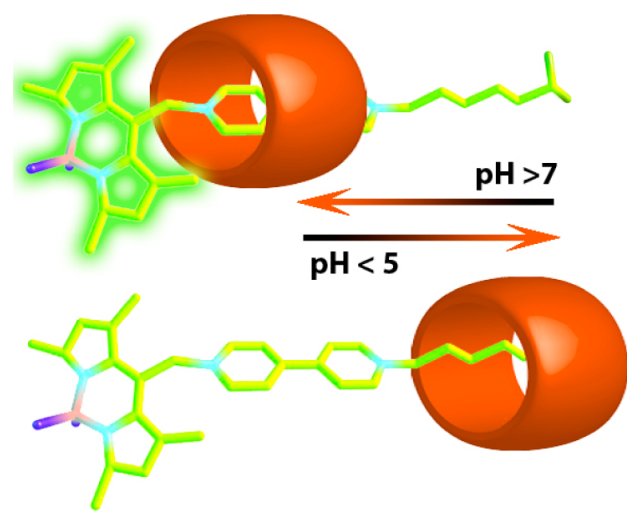

A bipyridinium dication-substituted Bodipy fluorophore, with a terminal carboxylic acid function, provides two alternative stations for cucurbit[7]uril. Changing pH from basic to acidic results in shuttling of the cucurbit[7]uril from one station to another. In addition, this shuttling is accompanied by a change in the emissive properties of the Bodipy dye, which is only observed in the presence of cucurbit[7]uril. More striking, is a demonstration of autonomous shuttling of the pseudorotaxane system in an oscillating pH system.

Bistable interlocked molecules are of great interest due to potential applications in molecular device manufacturing. ${ }^{1}$ Switching between these states can be achieved via

${ }^{\dagger}$ UNAM, Bilkent University

Department of Chemistry, Bilkent University

$\S$ Ataturk University

"Middle East Technical University

(1) (a) Yamada, M.; Kondo, M.; Mamiya, J. I.; Yu, Y. L.; Kinoshita, M.; Barrett, C. J.; Ikeda, T. Angew. Chem., Int. Ed. 2008, 47, 4986. (b) Pease, A. R.; Jeppesen, J. O.; Stoddart, J. F.; Luo, Y.; Collier, C. P.; Heath, J. R. Acc. Chem. Res. 2001, 34, 433. (c) Eelkema, R.; Pollard, M. M.; Vicario, J.; Katsonis, N.; Ramon, B. S.; Bastiaansen, C. W. M.; Broer, D. J.; Feringa, B. L. Nature 2006, 440, 163.

(2) (a) Badjic, J. D.; Balzani, V.; Credi, A.; Silvi, S.; Stoddart, J. F. Science 2004, 303, 1845. (b) Vella, S. J.; Tiburcio, J.; Loeb, S. J. Chem. Commun. 2007, 4752 .

(3) Deng, W. Q.; Flood, A. H.; Stoddart, J. F.; Goddard, W. A. J. Am. Chem. Soc. 2005, 127, 15994.

(4) (a) Brouwer, A. M.; Frochot, C.; Gatti, F. G.; Leigh, D. A.; Mottier, L.; Paolucci, F.; Roffia, S.; Wurpel, G. W. H. Science 2001, 291, 2124. (b) Saha, S.; Stoddart, J. F. Chem. Soc. Rev. 2007, 36, 77. acid-base chemistry, ${ }^{2}$ electrochemical, ${ }^{3}$ and/or photochemical $^{4}$ means. Such switchable systems are referred to as molecular machines, ${ }^{5}$ and recent years witnessed remarkable progress and increasing elegance in their design. There are also studies where some autonomous characters are built-in to these systems. ${ }^{6}$ The basic requirement for molecular machines is simple, a relatively rigid "axle" and a mobile "wheel" unit which can be switched to be stationed at two or more different locations along the axle, through noncovalent interactions.

(5) (a) Coskun, A.; Banaszak, M.; Astumian, R. D.; Stoddart, J. F.; Grzybowski, B. A. Chem. Soc. Rev. 2012, 41, 19. (b) Wang, J. B.; Feringa, B. L. Science 2011, 331, 1429. (c) Hess, H.; Dumont, E. L. P. Small 2011, 7, 1619. (d) Gong, H. Y.; Rambo, B. M.; Karnas, E.; Lynch, V. M.; Keller, K. M.; Sessler, J. L. J. Am. Chem. Soc. 2011, 133, 1526.

(6) (a) Balzani, V.; Clemente-Leon, M.; Credi, A.; Ferrer, B.; Venturi, M.; Flood, A. H.; Stoddart, J. F. Proc. Natl. Acad. Sci. U.S.A. 2006, 103, 1178. (b) Tanaka, K.; Kinbara, K. Mol. BioSyst. 2008, 4, 512. (c) Wilson, D. A.; Nolte, R. J. M.; van Hest, J. C. M. Nat. Chem. 2012, 4, 268. 
The very well-documented process of shuttling in these systems almost always requires some sort of an external stimulus. We were motivated to offer an alternative and potentially autonomous mechanism by coupling the shuttling process to an oscillating chemical reaction. Oscillating reactions ${ }^{7}$ represent an interesting class of dynamic selfassembly. The archetypical Belousov-Zhabotinsky (BZ) reaction ${ }^{8}$ behaves very well in closed systems, with a large number of identifiable concentration peaks and troughs before the oscillations dampen. Unfortunately, we could not make use of the Ce(III)-Ce(IV) couple. Metallocatenanes/rotaxanes looked promising, but there has to be a match between the oscillation frequency and the switching rate between the two states. ${ }^{9}$ In most cases, switching back to the original states is much slower than what seemed appropriate. We then focused on aqueous systems and thus $\mathrm{pH}$ oscillations. ${ }^{10} \mathrm{We}$ envisioned a situation where $\mathrm{pH}$ of a solution would be altered in a cyclic manner, switching the rotaxane between the two states. Thus, as long as the oscillation is sustained, the molecular machine would switch autonomously between these states.

There are only a few systems where $\mathrm{pH}$ oscillates in a controlled manner. Thiosulfate-sulfite-iodate is one of them, which displays high amplitude but irregular oscillations in batch systems. ${ }^{11}$ In a continuously stirred tank reactor, oscillations are well-behaved and essentially permanent, provided there is a steady supply of reactants and constant rate of removal for the products. Nevertheless, the batch system offered solid potential for a proof of principle study.
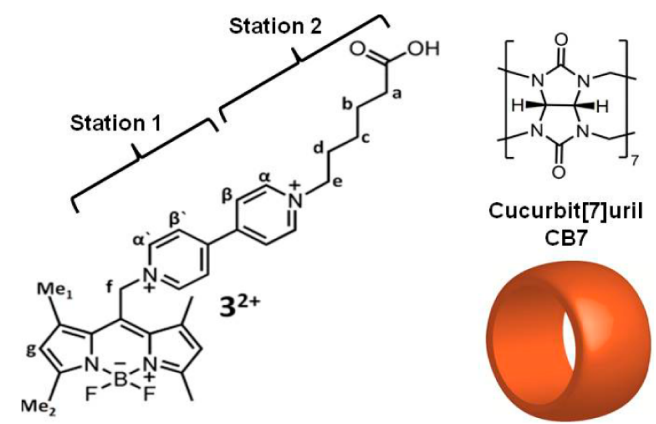

Figure 1. Structure of the fluorogenic "axle unit" with two potential stations for CB7.

To demonstrate the proof of principle operation of such an autonomous system, we set out to synthesize our target molecule shown in Figure 1. The wheel component is

(7) (a) Degn, H. J. Chem. Educ. 1972, 49, 302. (b) Noyes, R. M. J. Chem. Educ. 1989, 66, 190. (c) Nicolis, G.; Portnow, J. Chem. Rev. 1973, 73, 365.

(8) Zaikin, A. N.; Zhabotinsky, A. M. Nature 1970, 225, 535.

(9) Kern, J. M.; Raehm, L.; Sauvage, J.-P.; Divisia-Blohorn, B.; Vidal, P.-L. Inorg. Chem. 2000, 39, 1555-1560.

(10) (a) Rinker, R. G.; Lynn, S.; Mason, D. M.; Corcoran, W. H. Ind. Eng. Chem. Fundamen. 1965, 4, 282-288. (b) Matzusaki, I.; Woodson,

J. H.; Liebhafsky, H. A. Bull. Chem. Soc. Jpn. 1970, 43, 3317.

(11) Rabai, G.; Beck, M. T. J. Phys. Chem. 1988, 92, 4831-4835. cucurbit[7]uril (CB7). Cucurbiturils are an interesting class of molecules with excellent host properties. ${ }^{12}$ There are exciting examples of molecular switches and machines built using these host species. ${ }^{13} \mathrm{CB} 7$ seems more relevant with regard to molecular machine design since it can form very stable complexes with a number of aromatic amines and quaternized pyridinium and viologen species. ${ }^{14}$

The axle component of the pseudorotaxane system is a Bodipy derivative (Figure 1). Bodipy is a remarkable fluorophore with an amazing degree of versatility. ${ }^{15}$ Our previous work with the bipyridyl derivatives of Bodipy has shown ${ }^{16}$ that, when complexed to $\mathrm{Zn}$ (II), bipyridyl LUMO energy level changes, allowing an oxidative or reverse PET (photoinduced electron transfer) from the excited Bodipy unit, decreasing the intensity of emission. Later, a systematic study of the relative frontier orbital energy levels of Bodipy and the meso substituents ${ }^{17}$ proved our earlier suggestion. Thus, we expect that any interaction reducing the charge density on the pyridinium moiety would increase the emission intensity as a result of decreased reverse (oxidative) PET. The rest of our design was built on the results obtained by Kaifer. ${ }^{18}$ Carboxylic acid functionality linked to a bipyridinium dication moiety with pentamethylene spacers were shown to offer two binding sites for CB7. It was shown by NMR studies that, at neutral $\mathrm{pH}, \mathrm{CB} 7$ prefers the bipyridinium dication station, whereas under acidic conditions (when the carboxylate group is protonated), the carboxylic terminus becomes the preferred station. With these considerations in our design, we incorporated a carboxypentyl group as the second station. The Bodipy unit is the fluorescent reporter of the position of the wheel on the molecular axle, it is also a stopper, so at least from one end, $\mathrm{CB} 7-\mathbf{3}^{2+}$ complex is stoppered.

(12) (a) Masson, E.; Ling, X. X.; Joseph, R.; Kyeremeh-Mensah, L.; Lu, X. Y. RSC Adv. 2012, 2, 1213. (b) Lee, J. W.; Samal, S.; Selvapalam, N.; Kim, H. J.; Kim, K. Acc. Chem. Res. 2003, 36, 621. (c) Lagona, J.; Mukhopadhyay, P.; Chakrabarti, S.; Isaacs, L. Angew. Chem., Int. Ed 2005, 44, 4844. (d) Nau, W. M.; Scherman, O. A. Isr. J. Chem. 2011, $51,492$.

(13) (a) Ramalingam, V.; Urbach, A. R. Org. Lett. 2011, 13, 4898. (b) Sinha, M. K.; Reany, O.; Parvari, G.; Karmakar, A.; Keinan, E. Chem.-Eur. J. 2010, 16, 9056. (c) Ke, C. F.; Hou, S.; Zhang, H. Y.; Liu, Y.; Yang, K.; Feng, X. Z. Chem. Commun. 2007, 3374. (d) Kolman, V.; Khan, M. S. A.; Babinsky, M.; Marek, R.; Sindelar, V. Org. Lett. 2011, 13, 6148. (e) Zhang, H. Y.; Wang, Q. C.; Liu, M. H.; Ma, X.; Tian, H. Org. Lett. 2009, 11, 3234. (f) Gao, C.; Silvi, S.; Ma, X.; Tian, H.; Credi, A.; Venturi, M. Chem.-Eur. J. 2012, 18, 16911.

(14) (a) Freitag, M.; Gundlach, L.; Piotrowiak, P.; Galoppini, E. J. Am. Chem. Soc. 2012, 134, 3358. (b) Ivanov, D. A.; Petrov, N. K.; Nikitina, E. A.; Basilevsky, M. V.; Vedernikov, A. I.; Gromov, S. P.; Alfimov, M. V. J. Phys. Chem. A 2011, 115, 4505. (c) Kalmar, J.; Ellis, S. B.; Ashby, M. T.; Halterman, R. L. Org. Lett. 2012, 14, 3248. (d) Yuan, L.; Wang, R. B.; Macartney, D. H. J. Org. Chem. 2007, 72, 4539.

(15) (a) Loudet, A.; Burgess, K. Chem. Rev. 2007, 107, 4891. (b) Ziessel, R.; Ulrich, G.; Harriman, A. New J. Chem. 2007, 31, 496. (c) Bozdemir, O. A.; Yilmaz, M. D.; Buyukcakir, O.; Siemiarczuk, A.; Tutas, M.; Akkaya, E. U. New J. Chem. 2010, 34, 151. (d) Buyukcakir, O.; Bozdemir, O. A.; Kolemen, S.; Erbas, S.; Akkaya, E. U. Org. Lett. 2009, 11, 4644. (e) Kim, H. J.; Kim, S. H.; Kim, J. H.; Lee, E. H.; Kim,

K. W.; Kim, J. S. Bull. Korean Chem. Soc. 2008, 29, 1831.

(16) Turfan, B.; Akkaya, E. U. Org. Lett. 2002, 4, 2857.

(17) Ueno, T.; Urano, Y.; Kojima, H.; Nagano, T. J. Am. Chem. Soc. 2006, 128,10640 .

(18) (a) Sindelar, V.; Silvi, S.; Kaifer, A. E. Chem. Commun. 2006, 2185. (b) Kaifer, A. E.; Li, W.; Silvi, S.; Sindelar, V. Chem. Commun. 2012, 48, 6693. 
Synthesis was accomplished starting from the 8-chloromethyl-Bodipy derivative, and the preparation details of all new compounds are described in the Supporting Information (SI). The target Bodipy derivative has a reduced quantum yield as expected; reverse PET process competes effectively with the radiative de-excitation. The emission spectra of $\mathbf{3}^{\mathbf{2}+}$ in the presence of increasing concentrations of CB7 are highly instructive (Figure 2).

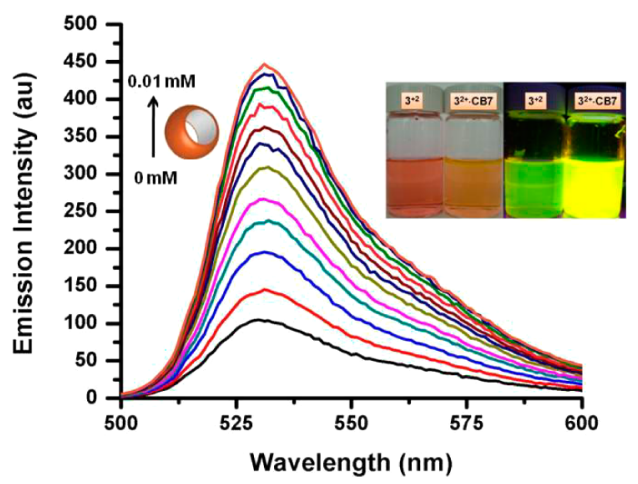

Figure 2. Emission spectra of compound $\mathbf{3}^{\mathbf{2}+}(0.01 \mathrm{mM}$, in $0.1 \mathrm{M}$ $\mathrm{NaCl}, 2 \% \mathrm{MeCN}$ in $\left.\mathrm{D}_{2} \mathrm{O}, \mathrm{pH} \sim 9\right)$ in the presence of increasing concentrations of CB7 $(0,0.1,0.2,0.3,0.4,0.50 .6,0.7,0.8,0.9$, $\left.1.0,1.1 \times 10^{-5} \mathrm{M}\right)$. Inset shows the appereance of solutions under ambient light (left) and under a hand-held $360 \mathrm{~nm} \mathrm{UV}$ lamp (right).

In the presence of $\mathrm{CB} 7$ at $10 \mu \mathrm{M}$ (1.0 equiv), there is more than a 4-fold increase in the emission intensity. The formation of an inclusion complex between the viologen dication and CB7 is also monitored by using mass spectrometry, which clearly shows the complexation (see SI). The complexation affinity was analyzed by the BenesiHildebrand treatment of the titration curve of $3^{2+}$ by CB7 (SI), the host-guest binding constant was obtained $(K=$ $\left.1.34 \times 10^{5} \mathrm{M}^{-1}\right)$.

Figure 3 shows the $\mathrm{pH}$-directed reversible oscillations in emission spectra with the inclusion complex of $\mathbf{3}^{\mathbf{2 +}}$ and $\mathrm{CB} 7$ as monitored by switching $\mathrm{pH}$ between $\mathrm{pH} \sim 2$ and $\sim 9$. As expected, the emission intensity is higher at neutral/ alkaline $\mathrm{pH}$ because, when the CB7 moiety encapsulates bipyridinium dication (station 1), ion-dipole interactions partially neutralize the positive charge on the bipyridinium, slowing the reverse PET and allowing the radiative transition to be the dominant mode of relaxation of the excited state. Thus, the spectra clearly show the switching of $\mathrm{CB} 7$ from one station to the other when $\mathrm{pH}$ is changed from 9.0 to 2. Note that, in the absence of $\mathrm{CB} 7$, the emission spectrum of $\mathbf{3}^{2+}$ in aqueous medium shows (SI) essentially no dependence on $\mathrm{pH}$ in the range of interest (pH 2 to 9).

To investigate the emission intensity variation as a function of $\mathrm{pH}$ (Figure 4), a 1:1 complex (the pseudorotaxane) was titrated in the $\mathrm{pH}$ range of 9 to 1.6. When the $\mathrm{p} K_{\mathrm{a}}$ of the carboxylic acid function is considered, the inflection point of the titration curve at $\mathrm{pH} 5$ is in agreement with the

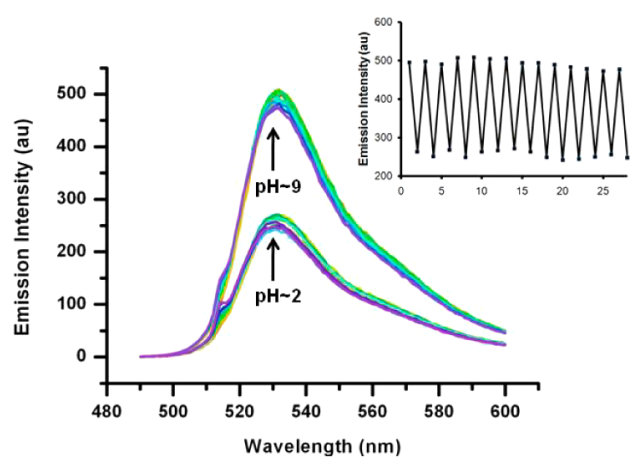

Figure 3. Emission spectra of solution compound $\mathbf{3}^{\mathbf{2}+}(0.01 \mathrm{mM}$, in $0.1 \mathrm{M} \mathrm{NaCl}, 2 \% \mathrm{MeCN}$ in $\mathrm{D}_{2} \mathrm{O}$ ) in the presence of 1.0 equiv of $\mathrm{CB} 7$ cycled between $\mathrm{pH} \sim 2$ and $\sim 9$. Inset shows emission vs $\mathrm{pH}$ $\sim 2$ to $\sim 9$ cycles recorded at $531 \mathrm{~nm}$.

literature data. ${ }^{17}$ Interestingly, the emission intensity of the complex is still higher than $\mathbf{3}^{\mathbf{2}}$.

The interaction between $\mathbf{3}^{\mathbf{2}+}$ and CB7 was also studied by ${ }^{1} \mathrm{H}$ NMR spectroscopy. Figure 5 shows the titration experiment of $\mathbf{3}^{\mathbf{2}}(3 \mathrm{mM})$ with $\mathrm{CB} 7$ in $0.1 \mathrm{M} \mathrm{NaCl} /$ $\mathrm{D}_{2} \mathrm{O} / \mathrm{CD}_{3} \mathrm{OD}(80: 20)$ solution ( $\mathrm{pD} \sim 8$ ). As previously reported, ${ }^{18,19}$ the addition of 1.0 equiv of CB7 resulted in an upfield shift of $\beta$ and $\beta^{\prime}$ protons of the viologen unit by 0.80 and $1.18 \mathrm{ppm}$, respectively. Although the $\alpha$ proton, as expected, shows minor shift in the peak position $(<0.1 \mathrm{ppm})$, the observed upfield shift for $\alpha^{\prime}$ is $0.7 \mathrm{ppm}$. This reveals that, in basic media, the Bodipy side of the viologen guest is pushed more into the cavity of CB7, which explains the unexpected large upfield displacement of the $\alpha^{\prime}$ protons and also the different upfield shifts of $\beta$ and $\beta^{\prime}$ protons. Because of this asymmetric arrangement within the pseudorotaxane, $\mathrm{Me}_{1}$ and $\mathrm{g}$ protons interact with the carbonyl oxygens of CB7 portals and undergo a downfield shift.

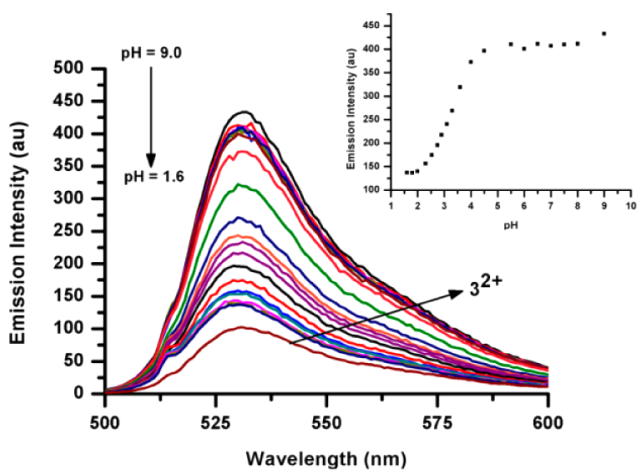

Figure 4. Emission spectra of compound $\mathbf{3}^{\mathbf{2}+}(0.01 \mathrm{mM}$, in $0.1 \mathrm{M}$ $\mathrm{NaCl}, 2 \% \mathrm{MeCN}$ in $\mathrm{D}_{2} \mathrm{O}$ ) with 1.0 equiv of $\mathrm{CB} 7$ with decreasing $\mathrm{pH}(9.0,8.0,7.5,7.0,6.5,6.0,5.5,4.5,4.0,3.6,3.3,3.1,2.9,2.7$, $2.5,2.3,2.0,1.8,1.6)$. Inset shows emission of $\mathbf{3}^{\mathbf{2}}$ complex as a function of $\mathrm{pH}$ recorded at $531 \mathrm{~nm}$. 

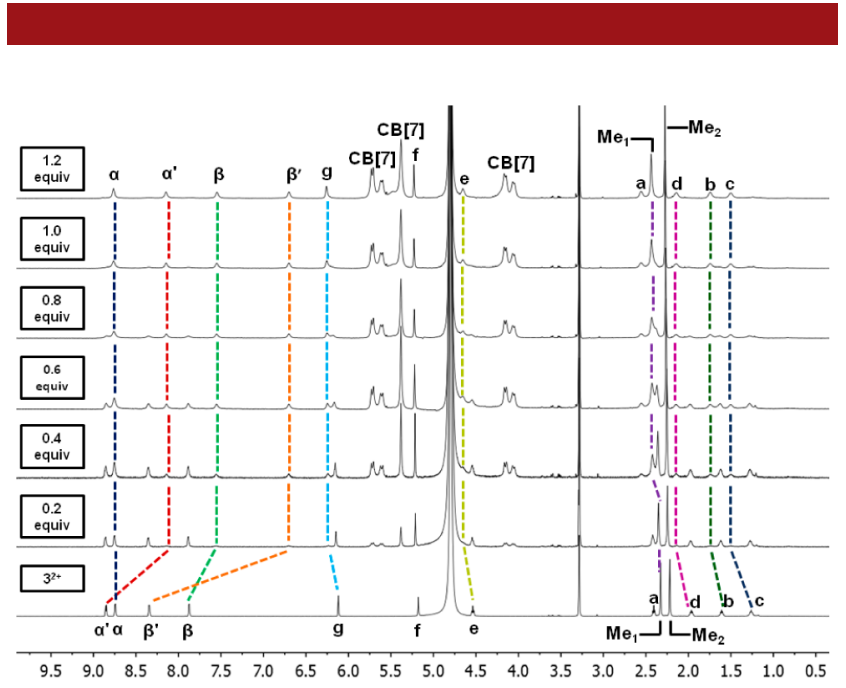

Figure 5. ${ }^{1} \mathrm{H}$ NMR spectra $\left(400 \mathrm{MHz}, 0.1 \mathrm{M} \mathrm{NaCl}\right.$ in $70: 30 \mathrm{D}_{2} \mathrm{O} /$ $\mathrm{CD}_{3} \mathrm{OD}$ at $\left.25^{\circ} \mathrm{C}\right)$ of $\mathbf{3}^{2+}(3.0 \mathrm{mM})$ in slightly basic media $\mathrm{pH} \sim 8$ with increasing concentrations of CB7 ( $0-1.2$ equiv).

This interaction is also predominant in the aliphatic region, especially e and d protons undergo a downfield shift. However, the more remote protons of the axle ( $a$ and $b$ ) are only slightly affected by the deshielding zone of the host and show a minor shift in peak positions. Furthermore, this asymmetrical intrusion of the viologen unit of the axle gives rise to splitting of $\mathrm{CB} 7$ protons. Formation of the inclusion complex between the guest $\left(3^{2+}\right)$ and host (CB7) molecules was also confirmed by 2D NOESY NMR spectroscopy (SI).

In acidic media, concomitant to the reduction in emission intensity (suggesting a preferential move away from the pyridinium cation immediately adjacent to the Bodipy unit), 2D NMR data show revealing changes (SI). Methylene hydrogens show off-diagonal (cross-peaks) with CB7 protons, a feature that does not show up in neutral/basic medium. Thus, it is apparent that CB7 remains mostly bound to the Bodipy axle, and yet it moves in the predicted direction.

Once we established $\mathrm{pH}$-mediated shuttling in aqueous solutions, we designed an experiment to realize similar shuttling in solution, but this time autonomously. In batch systems, $\mathrm{pH}$ oscillations for solutions containing thiosulfate, sulphite, and iodate ions are well-documented. We observed a small decrease in $\mathrm{pH}$ by 0.1 units, then a sharp drop of $3 \mathrm{pH}$ units to nearly $\mathrm{pH} 2.4$, and then oscillations die out, with $\mathrm{pH}$ reaching a constant value. The changes are highly reproducible. The switching was followed simultaneously by fluorescence spectroscopy and a $\mathrm{pH}$ meter: the first $8 \%$ increase in the emission intensity was observed, and at $360 \mathrm{~s}$ into the progression of the reaction, within a few seconds, a relatively fast drop $(-84 \%)$ in the

(19) Kim, H. J.; Jeon, W. S.; Ko, Y. H.; Kim, K. Proc. Natl. Acad. Sci. U.S.A. 2002, 99, 5007. emission intensity was observed. The emission changes were reproducible and juxtaposed very well with the changes in $\mathrm{pH}$ (Figure 6). In separate control experiments without CB7, no change in the emission was observed, eliminating any possibility of chemical processes altering the Bodipy emission. The batch $\mathrm{pH}$ oscillations were highly irregular and only sustained for just one or, at most, two cycles; nevertheless, our results clearly serve as a proof of principle for autonomous switching in a pseudorotaxane by coupling to an oscillating reaction.

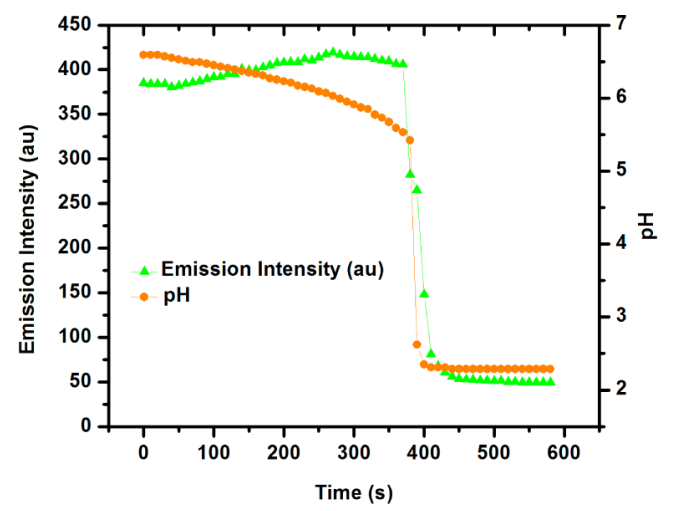

Figure 6. Plot of emission intensity and $\mathrm{pH}$ vs time obtained during the $\mathrm{pH}$ oscillation reaction coupled to the shuttling process. Thiosulfate $(17.5 \mathrm{mM})$, sulphite $(24.4 \mathrm{mM})$, and iodate ions $(10 \mathrm{mM})$. Oscillations were started by the addition of $22 \mathrm{mM} \mathrm{H}_{2} \mathrm{SO}_{4}$ to yield a final concentration of $5.5 \mathrm{mM}$ at the beginning of reaction. Concentration of CB7 (wheel) was $0.012 \mathrm{mM}$, and the Bodipy derivative (axle) was $0.01 \mathrm{mM} \mathrm{3} \mathbf{3}^{2+}$.

This is one of the rare demonstrations of a molecular shuttle system in which the "mobile" component is moving from one station to the other in a truly autonomous fashion. The coupling of $\mathrm{pH}$ oscillation to the shuttling process is clear, during which free energy of the oscillatory reactions is exploited. This kind of chemical coupling of an energetically favorable reaction (or set of reactions with complex kinetics) to molecular motion is reminiscent of many biological analogues and therefore highly exciting. The proof of principle study described here presents the first compelling evidence that oscillating reactions may provide such autonomy to molecular machines.

Acknowledgment. The authors gratefully acknowledge support from UNAM and Bilkent University for scholarships.

Supporting Information Available. Methods, experimental procedures, additional spectral data. This material is available free of charge via the Internet at http:// pubs.acs.org.

\footnotetext{
The authors declare no competing financial interest.
} 